\title{
Sistema anticolisión para invidentes usando redes neuronales evolutivas
}

\section{Anti-collision system for blind people using evolutionary neural networks}

DOI: https://doi.org/10.17981/ingecuc.14.2.2018.03

Artículo de investigación. Fecha de recepción:30/12/2017. Fecha de aceptación: 21/06/2018

\author{
Juan David Alvarado Coral \\ Universidad del Cauca. Popayán (Colombia) \\ juanalvarado@unicauca.edu.co
}

\author{
Elena Muñoz España \\ Universidad del Cauca. Popayán (Colombia) \\ elenam@unicauca.edu.co
}

Para citar este artículo:

J. D. Alvarado Coral y E. Muñoz España, "Sistema anticolisión para invidentes usando redes neuronales evolutivas," INGE CUC, vol. 14, no. 2, pp. 28-44, 2018. DOI: http://doi.org/10.17981/ingecuc.14.2.2018.03

\section{Resumen}

Introducción- El presente artículo muestra el diseño e implementación de un sistema anticolisión para invidentes usando redes neuronales artificiales evolutivas (RNAE).

Objetivo- Presentar la implementación de redes neuronales evolutivas en un sistema guía para invidentes para la detección de obstáculos estáticos y en movimiento.

Metodología- La metodología empleada se basa en la creación de redes neuronales artificiales a partir del algoritmo genético cooperativo coevolutivo (AGCC). Este se encarga de estructurar, modificar y entrenar las redes neuronales. Para ello utiliza la matriz de definición de red (MDR). Para la elaboración de una MDR se toma como base un cromosoma "parte del algoritmo genético". Una vez realizada la MDR, se crea una red neuronal artificial para luego ser entrenada.

Resultados- El programa realizó varias redes neuronales generando en cada ejecución 10 cromosomas, que al ser entrenados con el AGCC y aplicando la cooperatividad, se obtuvieron las mejores redes neuronales anticolisión teniendo en cuenta un tiempo definido, funcionando efectivamente para la detección de obstáculos estáticos y en movimiento.

Conclusiones- En el sistema anticolisión para invidentes se observó la eficacia de las redes neuronales para dar una respuesta, detectando objetos tanto estáticos como en movimiento y proporcionando así seguridad al invidente, evitándole colisionar con los objetos.

Palabras clave- Algoritmo genético cooperativo coevolutivo; invidente; sistema anticolisión; método neuroevolutivo; red neuronal artificial

\begin{abstract}
Introduction- This paper sets forth the design and implementation of an anti-collision system for visually-impaired people using evolutionary artificial neural networks (EANNs).

Objective- Present the implementation of evolutionary neural networks in a guide system for the visually-impaired people for the detection of static and moving obstacles.

Methodology- The methodology is based on the creation of artificial neural networks from the cooperative co-evolutionary genetic algorithm (CCGA), which is responsible for structuring, modifying and training neural networks. It uses the network definition matrix (NDM). The NDM is based on a chromosome which is "part of the genetic algorithm". Once the NDM is generated, an artificial neural network is created in order to be trained.
\end{abstract}

Results- The program accomplished several neural networks, generating 10 chromosomes in each execution. When the artificial neural networks were trained with the CCGA and the cooperation was included, the best anticollision neural networks were obtained considering a definite time. Hence, the anti-collision neural networks worked effectively for the detection of physical obstacles whether static or in motion.

Conclusions- In this anti-collision system for the visually impaired, the effectiveness of neural networks used to provide a suitable answer when detecting both static and moving objects was observed, thus, delivering security to visually impaired people by avoiding them collisions with objects.

Keywords- Cooperative Co-evolutionary Genetic Algorithm; visually impaired; anti-collision system; neuro-evolutionary method; artificial neural network 


\section{INTRODUCCIÓN}

Las personas con discapacidad visual, por lo general, utilizan bastones blancos para percibir el entorno y poder guiarse en ambientes internos y externos. La información que proporcionan las actuales herramientas de detección tiene falencias y no permite detectar obstáculos fácilmente ni con precisión, ya que, por ejemplo, los bastones no detectan obstáculos a nivel del pecho y la cara. Estas falencias también las presentan otros dispositivos para invidentes, limitándose a detectar obstáculos estáticos. Se hicieron bastantes investigaciones para definir la forma, ergonomía y facilidad de uso.

Con base en lo anterior, se creó este el sistema anticolisión para invidentes que consiste en un chaleco al que se le incorporaron 10 sensores ultrasónicos ubicados en la parte frontal y posterior.

El sistema anticolisión para invidentes se basó en el sistema de reconocimiento de obstáculos para movilidad de invidentes desarrollado en la Universidad del Cauca, el cual consiste de un bastón y sensores de ultrasonido. El sistema tiene dos escenarios definidos, el de control y el de usuario.

El sistema de control tiene la función de efectuar el reconocimiento del medio y lanzar una alerta oportuna en el instante requerido. Está compuesto por tres módulos: los sensores, el microcontrolador y el sistema de comunicación.

El sistema de usuario es desarrollado por el invidente quien maniobra el bastón y es beneficiario de las ayudas del sistema [1].

Una vez finalizada la construcción del sistema anticolisión, cuya base fueron los anteriores escenarios, detectó obstáculos estáticos de manera correcta con los 5 sensores frontales. De acuerdo con lo anterior, se implementó una red neuronal artificial evolutiva que permitiera controlar la parte estática y poner en funcionamiento los 10 sensores para detectar obstáculos en movimiento.

El artículo está organizado de la siguiente manera: en la sección II se presenta la revisión literaria, donde se encuentra la explicación para realizar las redes neuronales evolutivas. En la sección III, se explica la metodología, en donde se puede encontrar cómo se obtuvo la red neuronal evolutiva y su implementación para la detección de obstáculos estáticos y en movimiento. Los resultados están en la sección IV y, en la sección V, están las conclusiones y trabajo futuro.

\section{REVISIÓN LITERARIA}

Las Redes Neuronales Artificiales Evolutivas (RNAE) reciben este nombre al ser entrenadas con un algoritmo genético AG simple o cualquier tipo de algoritmo genético como el AGCC. Han sido un área de investigación clave en la última década del siglo XX y en la primera del siglo XXI [2],[3], proporcionando una plataforma mejorada para optimizar simultáneamente el rendimiento y la arquitectura de la red (número de nodos en la capa oculta y número de conexiones). En [4] propusieron que la Computación Evolutiva (CE) era una buena candidata para buscar en el espacio de arquitecturas debido a que la función de aptitud asociada con dicho espacio presenta ruido, es compleja, no diferenciable, multimodal y deceptiva. Desde entonces, muchos métodos de Programación Evolutiva (PE) han sido desarrollados para evolucionar redes neuronales, tales como [5], [6], [7]. En menor número de trabajos se emplean AG como en [8].

Existen tres formas de abordar el entrenamiento de una RNA con un AE:

1. Evolucionar los pesos de la RNA. En este caso, se fija la arquitectura de la red y se desarrolla una búsqueda global en el espacio de pesos. Los pesos son tradicionalmente representados con codificación real. En comparación con los algoritmos de retropropagación clásicos, pueden ser más lentos, pero no requieren el cálculo del gradiente.

2. Evolucionar la arquitectura de la RNA. Se parte, en este caso, de una inicialización aleatoria de los pesos y, tras la ejecución del AE, se suelen realizar varias iteraciones de un algoritmo de retropropagación clásico. La representación más natural para esta tarea es la codificación binaria. De cualquier forma, la optimización de la arquitectura es un proceso difícil, dando únicamente resultados aceptables en problemas relativamente pequeños.

3. Evolucionar simultáneamente tanto los pesos como la arquitectura de la RNA. Esta estrategia pretende reunir las ventajas de las dos anteriores. El principal inconveniente radica en la dificultad asociada al entrenamiento de los modelos de red. Hoy en día, es una de las técnicas más interesantes de RNAE [9].

El AGCC comienza con una generación igual a cero, el número de especies es dado de forma aleatoria por el mismo programa, se inicializa la población en la que un individuo de la misma población representa un cromosoma y a continuación se presenta el algoritmo [10], en el que $P s$ es la población de una especie $s$. Su generación se inicializa en $0, P$ 's es la población seleccionada de la generación anterior basada en el fitness.

\footnotetext{
Algoritmo AGCC

gen $=0 ; \%$ Se inicializa la generación para cada especie s, se hace

Ps $($ gen $)=$ se inicializa la población aleatoriamente por cada especie.

Se evalúa cada individuo en PS (gen) fin ciclo para mientras el criterio de terminación $=$ sea falso gen $=$ gen +1

para cada especie $\mathbf{s}$ hace lo siguiente

se selecciona P's(gen) de $\mathbf{P}_{\text {s(gen-1) basado en el fitness }}$ se aplica los operadores de cruce y mutación para P's (gen) se evalúa cada individuo en la P's(gen) se selecciona PS (gen) de la P's(gen) y la $\mathbf{P s}$ (gen-1)

fin ciclo para

fin ciclo mientras
} 
Un cromosoma está formado por la topología y los parámetros de la RNA. La topología se determina con base en la información contenida en la primera parte del cromosoma. Los valores binarios de esta parte se copian de forma redireccionada en la MDR, la cual contiene toda la información para realizar una red neuronal recurrente; un solo bit corresponde a un único elemento en la matriz. Cuando el número de bits es insuficiente para completar la matriz, la secuencia completa de bits se utiliza de nuevo. Los parámetros del segundo par al cromosoma se introducen sucesivamente en la MDR. En este caso, solo se modifican los elementos iguales a uno [2].

La forma de evaluar en el AGCC depende del problema a solucionar. Acabado el primer ciclo de programación, sigue el conteo de generaciones para luego seleccionar los individuos según el criterio de evaluación. En la selección de individuos se aplican técnicas como la selección por ruleta, por torneo, elitismo, etc. De forma similar, en el cruce existen técnicas como el cruce en un punto, dos puntos, uniforme, etc. Por lo general, en la parte de mutación, un pequeño porcentaje de la población es mutada.

La cooperatividad y la coevolución se da cuando un módulo de redes neuronales artificiales está conformado por un conjunto de subredes de RNA sin conexión y un vector compuesto de registros de salida numerados. La tarea de la sub RNA es producir colectivamente una salida. Cada registro corresponde a diferentes salidas y estas son actualizadas independientemente de otros registros. Una simple ejecución del conjunto de sub RNA genera un valor para un registro. En consecuencia, para obtener una salida completa a partir de las entradas de la red neuronal artificial, las sub RNA tienen que ejecutarse un número de veces. En cada ejecución, únicamente una subred es seleccionada para modificar un registro. Para seleccionar una sub RNA activa, un proceso de negociación entre todas las subredes se lleva a cabo. La sub RNA con la mayor fuerza de negociación tiene permiso para cambiar un valor de un registro seleccionado [2].

En el AGCC, cada parte de una solución evoluciona en una población separada. Para formar una solución completa es necesario seleccionar representantes de cada población (usualmente el mejor de todos) y combinarlos.

\section{III.METODOLOGÍA}

La red neuronal evolutiva que se desarrolló en esta investigación fue elaborada y entrenada con el método de evolucionar simultáneamente tanto los pesos como la arquitectura de la RNA. La RNA se obtuvo de la siguiente manera:

\section{A. Obtención de la red neuronal evolutiva}

El diseño del software se realiza en Matlab basándose en el AGCC. Primero, se crea el número de especies, para este caso, la solución del problema puede ser de 6 a 10 especies. Luego se crea una población aleatoria de 30 individuos; por cada población se extrae un número de individuos, como mínimo debe ser un representante por cada población.

\section{1) Elaboración de la población}

En la fig. 1 se puede observar parte del código para la elaboración de la población.

Cada individuo representa un cromosoma. La topología del cromosoma se formó con números binarios y los parámetros con números reales aleatorios en el rango de -1 a 1. Luego, estos cromosomas pasan a ser evaluados, y esto se hace mediante la ejecución de la red neuronal teniendo en cuenta el número de neuronas, el tipo de neurona, topología y el número de especies.

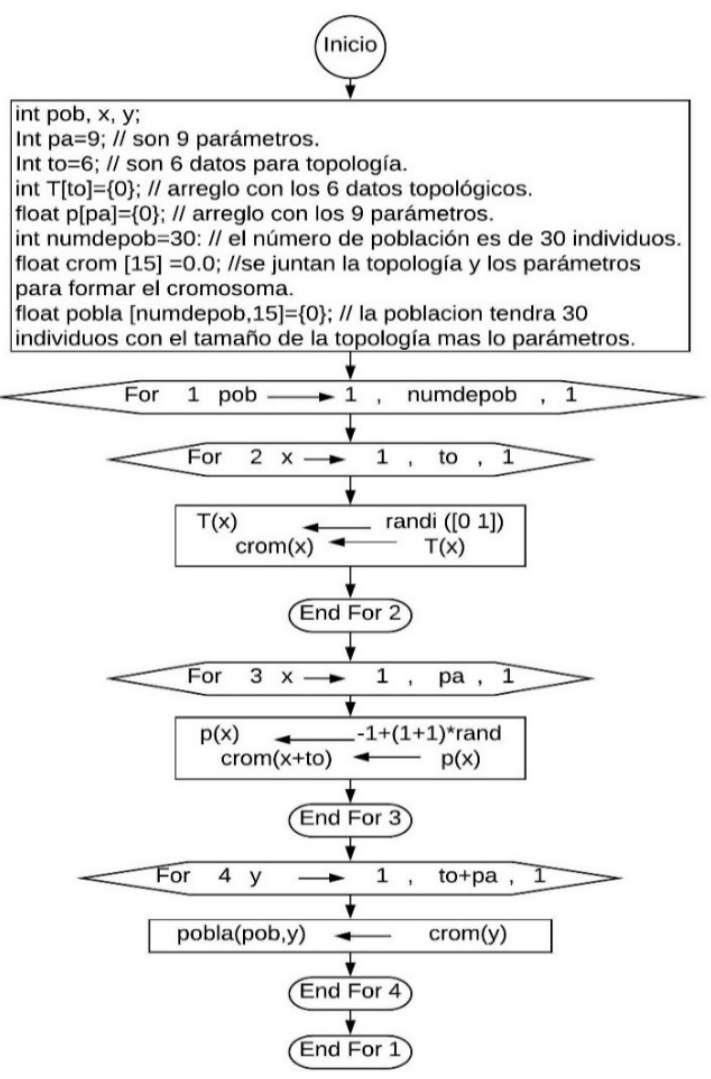

Fig. 1. Diagrama de flujo para crear poblaciones. Fuente: autores.

En la Tabla 1 y Tabla 2, se toma un individuo de la población 1, más específicamente el cromosoma 5 . 
Tabla 1. Evaluación de CADa INDIVIDUO EN UNA POBLACióN: TOPOLOGÍA

\begin{tabular}{|c|c|c|c|c|c|c|}
\hline $\mathrm{N}^{\circ}$ & \multicolumn{6}{|c|}{ Topología } \\
\hline 1 & 1 & 1 & 0 & 1 & 1 & 0 \\
\hline 2 & 1 & 1 & 1 & 1 & 0 & 0 \\
\hline 3 & 0 & 0 & 1 & 1 & 0 & 1 \\
\hline 4 & 1 & 1 & 0 & 0 & 0 & 0 \\
\hline 5 & 0 & 1 & 1 & 1 & 1 & 0 \\
\hline 6 & 1 & 1 & 1 & 1 & 1 & 1 \\
\hline 7 & 0 & 0 & 0 & 1 & 0 & 0 \\
\hline 8 & 0 & 0 & 1 & 1 & 1 & 0 \\
\hline 9 & 0 & 1 & 1 & 1 & 1 & 0 \\
\hline 10 & 0 & 1 & 1 & 1 & 0 & 1 \\
\hline 11 & 1 & 0 & 0 & 0 & 0 & 1 \\
\hline 12 & 1 & 0 & 1 & 0 & 1 & 1 \\
\hline 13 & 1 & 1 & 1 & 1 & 1 & 1 \\
\hline
\end{tabular}

Fuente: autores.

TABla 2. Evaluación de CADA INDividuo En UNA POBLACIÓN: Parámetros

\begin{tabular}{|c|c|c|c|c|c|c|c|c|c|}
\hline $\mathrm{N}^{\circ}$ & \multicolumn{7}{|c|}{ Parámetros } \\
\hline 1 & $-0,14$ & 0,60 & 0,38 & 0,80 & $-0,75$ & $-0,97$ & $-0,60$ & $-0,56$ & $-0,22$ \\
\hline 2 & $-0,09$ & 0,60 & 0,70 & 0,26 & $-0,27$ & $-0,93$ & 0,86 & 0,80 & 0,97 \\
\hline 3 & $-0,84$ & $-0,47$ & $-0,40$ & 0,85 & 0,68 & 0,58 & 0,59 & 0,85 & 0,38 \\
\hline 4 & $-0,45$ & $-0,06$ & $-0,79$ & 0,16 & $-0,92$ & 0,60 & 0,39 & $-0,31$ & $-0,48$ \\
\hline 5 & 0,37 & 0,79 & 0,72 & 0,45 & 0,81 & 0,80 & 0,32 & 0,74 & 0,87 \\
\hline 6 & 0,09 & $-0,04$ & $-0,43$ & $-0,19$ & $-0,31$ & 0,99 & 0,02 & $-0,24$ & 0,40 \\
\hline 7 & $-0,66$ & $-0,97$ & $-0,99$ & 0,02 & 0,67 & 0,95 & $-0,28$ & 0,78 & $-0,47$ \\
\hline 8 & 0,50 & $-0,03$ & 0,99 & $-0,03$ & $-0,81$ & $-0,01$ & $-0,43$ & $-0,60$ & $-0,37$ \\
\hline 9 & $-0,47$ & $-0,86$ & $-0,93$ & $-0,36$ & 0,38 & 0,88 & 0,11 & $-0,57$ & $-0,68$ \\
\hline 10 & 0,95 & $-0,07$ & 0,74 & $-0,01$ & 0,99 & 0,48 & $-0,58$ & $-0,17$ & $-0,80$ \\
\hline 11 & $-0,36$ & 0,76 & $-0,63$ & 0,68 & 0,16 & 0,12 & $-0,03$ & 0,23 & $-0,54$ \\
\hline 12 & $-0,05$ & $-0,29$ & 0,41 & 0,54 & 0,45 & 0,89 & 0,71 & $-0,79$ & 0,27 \\
\hline 13 & $-0,27$ & $-0,88$ & 0,06 & $-0,89$ & 0,83 & 0,93 & $-0,71$ & $-0,74$ & 0,05 \\
\hline
\end{tabular}

Fuente: autores.

Todos los individuos de la población deben pasar por el proceso de evaluación, en este caso se toma como ejemplo el cromosoma 5 . El cual se evalúo previamente por el programa y aprobó la evaluación. A continuación se explica este proceso.

\section{- Creación de una MDR}

Se forman dos matrices, una con la topología que se muestra en la Tabla 3 y otra con los parámetros de la Tabla 4, los que, a su vez, se multiplican elemento por elemento para formar la MDR, como se muestra en la Tabla 5.

TABla 3. Matriz topológica

\begin{tabular}{|l|l|l|l|l|l|l|l|}
\hline 0 & 1 & 1 & 1 & 1 & 0 & 0 & 1 \\
\hline 1 & 1 & 1 & 0 & 0 & 1 & 1 & 1 \\
\hline 1 & 0 & 0 & 1 & 1 & 1 & 1 & 0 \\
\hline 0 & 1 & 1 & 1 & 1 & 0 & 0 & 1 \\
\hline 1 & 1 & 1 & 0 & 0 & 1 & 1 & 1 \\
\hline 1 & 0 & 0 & 1 & 1 & 1 & 1 & 0 \\
\hline
\end{tabular}

Fuente: autores.

Tabla 4. Matriz de parámetros

\begin{tabular}{|c|c|c|c|c|c|c|c|}
\hline 0,37 & 0,79 & 0,72 & 0,45 & 0,81 & 0,80 & 0,32 & 0,74 \\
\hline 0,87 & 0,37 & 0,79 & 0,72 & 0,45 & 0,81 & 0,80 & 0,32 \\
\hline 0,74 & 0,87 & 0,37 & 0,79 & 0,72 & 0,45 & 0,81 & 0,80 \\
\hline 0,32 & 0,74 & 0,87 & 0,37 & 0,79 & 0,72 & 0,45 & 0,81 \\
\hline 0,80 & 0,32 & 0,74 & 0,87 & 0,37 & 0,79 & 0,72 & 0,45 \\
\hline 0,81 & 0,80 & 0,32 & 0,74 & 0,87 & 0,37 & 0,79 & 0,72 \\
\hline
\end{tabular}

Fuente: autores.

Tabla 5. Matriz de Definición DE RED

\begin{tabular}{l|c|c|c|c|c|c|c|c|}
\multicolumn{1}{c}{1} & \multicolumn{1}{c}{2} & 3 & 4 & 5 & 6 & Bias & Función \\
\cline { 2 - 9 } & 0,00 & 0,79 & 0,72 & 0,45 & 0,81 & 0,00 & 0,00 & 0,74 \\
\cline { 2 - 9 } $\mathbf{2}$ & 0,87 & 0,37 & 0,79 & 0,00 & 0,00 & 0,81 & 0,80 & 0,32 \\
\cline { 2 - 9 } & 0,74 & 0,00 & 0,00 & 0,79 & 0,72 & 0,45 & 0,81 & 0,00 \\
\cline { 2 - 9 } & 0,00 & 0,74 & 0,87 & 0,37 & 0,79 & 0,00 & 0,00 & 0,81 \\
\hline & 0,80 & 0,32 & 0,74 & 0,00 & 0,00 & 0,79 & 0,72 & 0,45 \\
\hline & 0,81 & 0,00 & 0,00 & 0,74 & 0,87 & 0,37 & 0,79 & 0,00 \\
\hline
\end{tabular}

El tamaño de la MDR define el número de neuronas, en este caso son 6 neuronas. La función de activación es dada por la siguiente condición:

$$
\text { si abs }(f)>0,5 \rightarrow \text { la función es de tipo lineal }
$$

si abs $(f)<0,5 \rightarrow$ la función es de tipo sigmoide (2)

\section{- Neuronas de capa oculta}

Para definir el tamaño de la red neuronal se incrementan las neuronas de capa oculta hasta encontrar el resultado dado por la ejecución de la red neuronal artificial, en caso contrario, se genera una nueva población y se cambia de individuo. En las tablas 6 y 7, se observan dos MDR elaboradas por el programa, donde la Tabla 7 es la óptima porque se ha 
acercado la respuesta de la red neuronal artificial a la condición de evaluación.

TABLA 6. MDR 1 CON 2 CAPAS OCULTAS

\begin{tabular}{|c|c|c|c|c|c|c|}
\cline { 2 - 7 } \multicolumn{1}{c|}{} & 1 & 2 & 3 & 4 & Bias & Función \\
\hline $\mathbf{1}$ & 0,16 & 0,94 & 0,71 & 0,00 & 0,34 & 0,00 \\
\hline $\mathbf{2}$ & 0,60 & $-0,30$ & $-0,95$ & 0,00 & 0,94 & 0,00 \\
\hline $\mathbf{3}$ & 0,44 & 0,34 & 0,59 & 0,00 & $-0,30$ & 0,00 \\
\hline $\mathbf{4}$ & 0,16 & 0,94 & 0,71 & 0,00 & 0,34 & 0,00 \\
\hline
\end{tabular}

Fuente: autores.

TABLA 7. MDR 2 CON 3 CAPAS OCULTAS

\begin{tabular}{l|c|c|c|c|c|c|c|}
\multicolumn{1}{c}{} & \multicolumn{1}{c}{$\mathbf{1}$} & \multicolumn{1}{c}{$\mathbf{3}$} & $\mathbf{4}$ & $\mathbf{5}$ & \multicolumn{1}{c}{ Bias } & Función \\
\cline { 2 - 8 } $\mathbf{1}$ & 0,16 & 0,94 & 0,71 & 0,00 & 0,34 & 0,00 & 0,60 \\
\cline { 2 - 8 } $\mathbf{2}$ & $-0,30$ & $-0,95$ & 0,00 & 0,94 & 0,00 & 0,44 & 0,34 \\
\cline { 2 - 8 } $\mathbf{3}$ & 0,59 & 0,00 & $-0,30$ & 0,00 & 0,16 & 0,94 & 0,71 \\
\cline { 2 - 8 } $\mathbf{4}$ & 0,00 & 0,34 & 0,00 & 0,60 & $-0,30$ & $-0,95$ & 0,00 \\
\cline { 2 - 8 } $\mathbf{5}$ & 0,94 & 0,00 & 0,44 & 0,34 & 0,59 & 0,00 & $-0,30$ \\
\hline
\end{tabular}

Fuente: autores.

La red neuronal resultante de la MDR de la tabla 4 se observa en la fig. 2 .

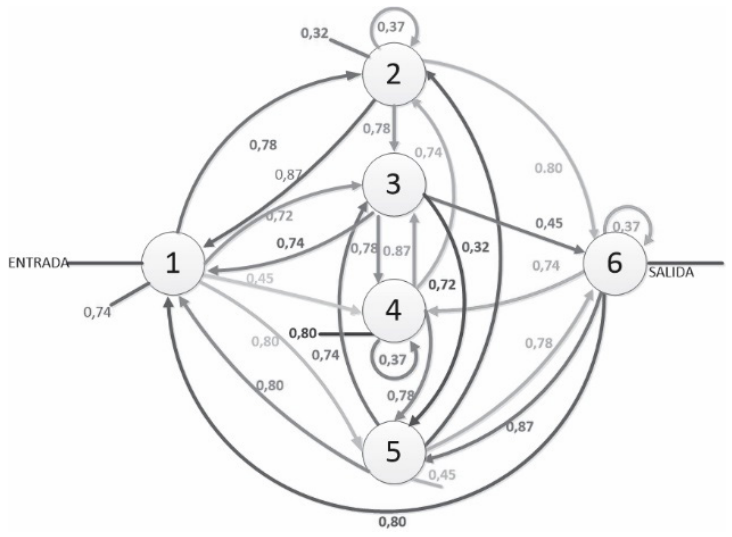

Fig. 2. Red neuronal recurrente. Fuente: autores.

Se toma el cromosoma número 5 porque la respuesta de la red se encuentra en el rango de 1 a -1 , el cual es el rango en el que se espera encontrar la respuesta de solución al problema.

\section{2) Aplicación del AGCC a la siguiente generación}

Se crea una nueva generación a partir de la primera. Con el método anteriormente descrito se realiza la creación de varias generaciones para, posteriormente, realizar el proceso de cruce, selección, mutación y cooperación.

\section{- Selección}

Una vez encontrados los mejores individuos, estos son seleccionados y categorizados según su valor de aptitud o fitness para luego ser recombinados.

El valor de aptitud empleado es el siguiente:

$F 1(r e d)=\left\{\begin{array}{lr}d s>-1 & (\text { Condición a) } \\ d s<1 & (\text { Condición b) } \\ d s>\left(\left(\frac{-d s m-d s c}{2}\right)+d s m\right. & (\text { Condición c }) \\ d s<\left(\left(\frac{-d s m-d s c}{2}\right)+d s m\right. & (\text { Condición } d) \\ d s \leq 0 & (\text { Condición e })\end{array}\right.$

$F 2($ red $)=\left\{\begin{array}{lr}F 1(\text { red }) & (\text { Condición } a, b, c, d) \\ d s \geq 0 & (\text { Condición } e)\end{array}\right.$

Donde es el dato del sensor del objeto detectado, es el dato máximo del sensor, $d s c$ es el dato mínimo del sensor de detección de obstáculos.

En las ecuaciones (3) y (4), las condiciones $a$ y $b$ son para asegurar que gran parte de individuos de cualquier población puedan ingresar en la primera parte de la evaluación, ya que en su material genético puede estar la respuesta que se busca.

La condición $c$ es de alerta de objeto en movimiento a menos de $6 \mathrm{~m}$.

La condición $d$ es de alerta de objeto en movimiento a menos de $3 \mathrm{~m}$.

La condición $e$ es para asegurar la convergencia de la red.

\section{- Cruce}

La recombinación se realiza en 2 puntos. Los padres seleccionados se muestran en la tabla 8 y los hijos resultantes se muestran en la tabla 9. El primer punto de corte se encuentra en el índice 5 y el segundo en el 10.

Tabla 8. Padres Seleccionados

\begin{tabular}{|c|c|c|c|c|c|c|c|c|c|c|c|c|c|c|}
\hline \multicolumn{7}{|c|}{ Topología } & \multicolumn{10}{|c|}{ Parámetros } \\
\hline 0 & 1 & 1 & 1 & 1 & 0 & 0,37 & 0,79 & 0,72 & 0,45 & 0,81 & 0,80 & 0,32 & 0,74 & 0,87 \\
\hline 1 & 1 & 0 & 1 & 1 & 1 & $-0,14$ & 0,60 & 0,38 & 0,80 & $-0,75$ & $-0,97$ & $-0,60$ & $-0,56$ & $-0,22$ \\
\hline
\end{tabular}

Fuente: autores. 
TABLA 9. HiJos

\begin{tabular}{|c|c|c|c|c|c|c|c|c|c|c|c|c|c|c|}
\hline \multicolumn{1}{|c|}{ Topología } & \multicolumn{10}{|c|}{ Parámetros } \\
\hline 0 & 1 & 1 & 1 & 1 & 1 & $-0,14$ & 0,60 & 0,38 & 0,80 & 0,81 & 0,80 & 0,32 & 0,74 & 0,87 \\
\hline 1 & 1 & 0 & 1 & 1 & 0 & 0,37 & 0,79 & 0,72 & 0,45 & $-0,75$ & $-0,97$ & $-0,60$ & $-0,56$ & $-0,22$ \\
\hline
\end{tabular}

Fuente: autores.

\section{- Mutación}

Algunos de los individuos con bajo índice de mutación también pasarán a ser evaluados, creando una nueva población. El índice de mutación empleado es del $6 \%$.

\section{- Cooperatividad}

Después se aplica la cooperatividad: el individuo que obtenga mejores resultados ayudará al que esté con bajo valor de aptitud; si no se encuentra la respuesta, pasarán de nuevo los mejores individuos a ser seleccionados en una nueva generación, es decir, si la respuesta no es la deseada volverán a la parte de selección hasta obtener la respuesta deseada.

\section{3) Cromosomas obtenidos}

A continuación, se muestran los cromosomas obtenidos para la detección de objetos estáticos en la tabla 10 y en la tabla 11 se indica el cromosoma para la detección de objetos en movimiento.

La topología y parámetros que hacen parte de cada cromosoma son los ideales para el correcto funcionamiento en la detección de obstáculos tanto estáticos como en movimiento. Para la detección de obstáculos estáticos, se tomaron 5 cromosomas, uno para cada sensor. Teniendo en cuenta su ubicación en el cuerpo, estos requerían de rangos de detección diferentes debido al ángulo de posición.

\section{B. Implementación de la red neuronal evolutiva}

Una vez obtenidos los cromosomas que contienen toda la información para la elaboración de la red neuronal artificial, se realiza la codificación en un módulo Arduino. Luego, se procede a realizar los pasos de creación de red neuronal artificial vistos anteriormente, con la única diferencia de que ya no se crean poblaciones y se crean las MDR. Para esto, se deben tener buenas bases en programación, ya que el mal uso de variables hace que haya saturación en la memoria de Arduino, sobre todo cuando se tienen que manejar matrices. El código actual usó el $16 \%$ de almacenamiento del programa y $14 \%$ de la memoria dinámica en un Arduino Mega. El tiempo de respuesta de los 10 sensores con conexión bluetooth entre sensado y sensado es de $757 \mathrm{~ms}$, y la respuesta es dada a través de auriculares. A continuación, se muestra la ubicación de los sensores en el chaleco en la fig. 3 .

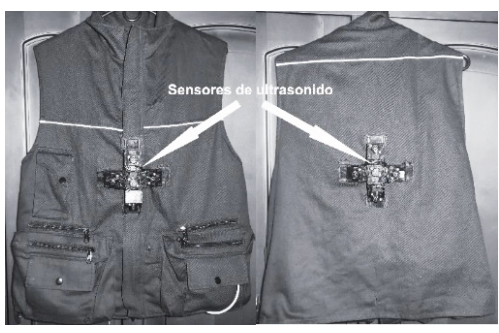

Fig. 3. Chaleco con sensores. Fuente: autores.

Tabla 10. Cromosomas para la detección de obJetos estáticos.

\begin{tabular}{|c|c|c|c|c|c|c|c|c|c|c|c|c|c|c|}
\hline \multicolumn{1}{|c|}{ Topología } & \multicolumn{10}{c|}{ Parámetros } \\
\hline 0 & 0 & 0 & 1 & 1 & 1 & 0.95 & 0.11 & -0.37 & -0.14 & 0.40 & -0.64 & -0.94 & 0.15 & -0.18 \\
\hline 1 & 1 & 0 & 1 & 0 & 0 & -0.61 & -0.77 & 0.56 & -0.01 & -0.22 & -0.56 & -0.37 & -0.90 & -0.60 \\
\hline 0 & 1 & 0 & 1 & 1 & 0 & 0.85 & -0.12 & -0.60 & 0.18 & -0.68 & -0.46 & 0.06 & 0.42 & -0.84 \\
\hline 0 & 0 & 1 & 1 & 1 & 1 & -0.62 & -0.09 & 0.11 & 0.78 & -0.11 & -0.04 & 0.07 & 0.37 & -0.97 \\
\hline 1 & 0 & 1 & 1 & 1 & 1 & -0.52 & -0.12 & 0.19 & 0.38 & 0.32 & -0.55 & -0.13 & -0.17 & -0.10 \\
\hline
\end{tabular}

Tabla 11. Cromosoma para la detección de objetos en movimiento.

\begin{tabular}{|c|c|c|c|c|c|c|c|c|c|c|c|c|c|c|}
\hline \multicolumn{1}{|c|}{ Topología } & \multicolumn{10}{c|}{ Parámetros } \\
\hline 1 & 1 & 1 & 0 & 0 & 0 & 0.35 & -0.35 & -0.90 & 0.64 & -0.48 & -0.26 & 0.76 & 0.66 & -0.44 \\
\hline
\end{tabular}

Fuente: autores. 
Los sensores de ultrasonido son ubicados tanto en la parte frontal como en la espalda para detectar objetos con movimiento y evadir colisiones en todas las direcciones. Se conectan a un módulo Arduino.

La distribución de los sensores en el chaleco se muestra en la tabla 12 .

\section{TABLA 12. UBICACIÓN DE LOS SENSORES}

\begin{tabular}{|c|c|}
\hline Sensor & Ubicación \\
\hline S1 & Arriba parte frontal \\
\hline S2 & Frente parte frontal \\
\hline S3 & Abajo parte frontal \\
\hline S4 & Derecha parte frontal \\
\hline S5 & Izquierda parte frontal \\
\hline S6 & Arriba parte posterior \\
\hline S7 & Frente parte posterior \\
\hline S8 & Abajo parte posterior \\
\hline S9 & Derecha parte posterior \\
\hline S10 & Izquierda parte posterior \\
\hline
\end{tabular}

Fuente: autores.

\section{Resultados}

Se realizaron pruebas para la detección de objetos estáticos y en movimiento con un escenario para cada prueba.

En el escenario para la detección de objetos estáticos se realizó la prueba con 10 personas, quienes se desplazaron por un escenario desconocido para ellas en el cual se ubicaron obstáculos (cajas), previamente dispuestas, para que los participantes se desplazarán uno a uno, haciendo uso del sistema.

Los participantes en el escenario se clasifican teniendo en cuenta su edad y su sexo, haciendo énfasis en que los primeros 5 son invidentes, los cuales están relacionados en la tabla 13.

Tabla 13. Participantes

\begin{tabular}{|c|c|c|}
\hline Participante & Sexo & Edad \\
\hline 1 & Femenino & 33 \\
\hline 2 & Femenino & 41 \\
\hline 3 & Femenino & 34 \\
\hline 4 & Masculino & 39 \\
\hline 5 & Masculino & 45 \\
\hline 6 & Masculino & 30 \\
\hline 7 & Masculino & 14 \\
\hline 8 & Femenino & 47 \\
\hline 9 & Femenino & 14 \\
\hline 10 & Femenino & 35 \\
\hline
\end{tabular}

Fuente: autores.
En la fig. 4 se muestra el escenario planteado con sus respectivas trayectorias y en la fig. 5 un invidente recorriendo el escenario.

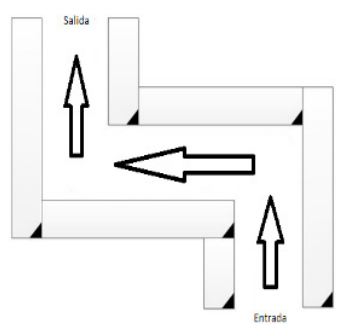

Fig. 4. Escenario 1. Fuente: autores.

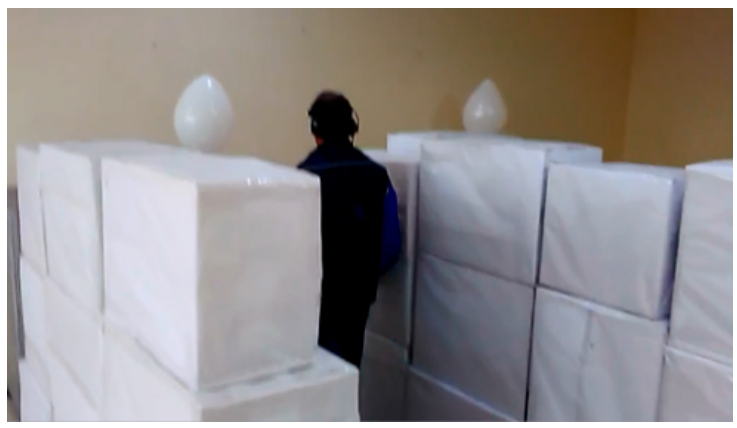

Fig. 5. Invidente recorriendo el escenario 1. Fuente: autores.

En la fig. 6 se puede observar que el sistema le advirtió al invidente número 1 acerca del primer obstáculo en el dato 23 detectado por la red. En el rango de 23 a 100 datos, se desplazó por la primera recta del escenario; de 100 a 144, hizo un giro a la derecha; de 144 a 188, realizó un giro a la izquierda; entre 199 y 265, avanzó por la segunda recta; de 276 a 331, giró su cuerpo; de 342 a 386, caminó por la última recta.

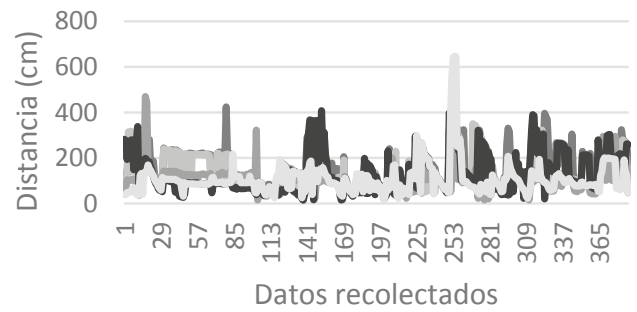

Fig. 6. Datos del participante 1 . Fuente: autores.

En la fig. 7, se puede apreciar que el sistema le advirtió al invidente número 2 acerca del primer obstáculo en el dato 19. En el rango de 19 a 73, caminó por la primera recta; de 79 a 97 , hizo un giro a la izquierda; entre 97 y 157, se movió por la segunda recta; de 157 a 193, giró su cuerpo; de 193 a 211, se desplazó por la última recta. 

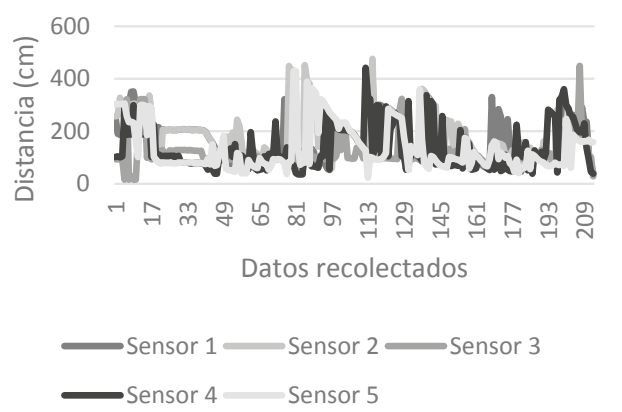

Fig. 7. Datos del participante 2 . Fuente: autores.

En la fig. 8, se puede ver que el sistema le advirtió al invidente número 3 acerca del primer obstáculo en el dato 1 . En el rango de 1 a 46 avanzó por la primera recta; de 46 a 64 , hizo un giro a la izquierda; entre 64 y 172 , se dirigió por la segunda recta; de 172 a 226, giró su cuerpo; de 226 a 316, caminó por la última recta.

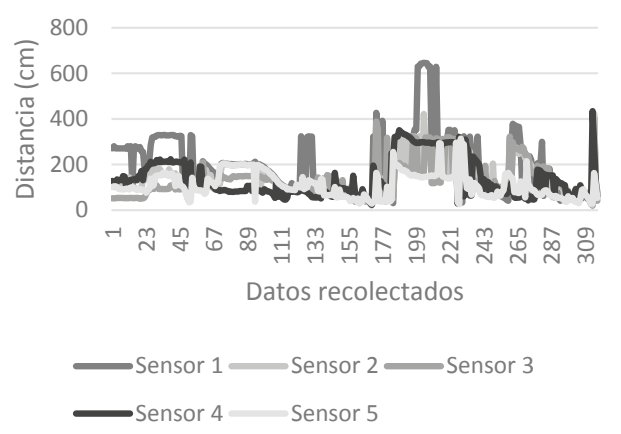

Fig. 8. Datos del participante 3. Fuente: autores.

En la fig. 9, se puede deducir que el sistema le advirtió al invidente número 4 acerca del primer obstáculo en los datos 1 a 23. En el rango de 34 a 155 se movió por la primera recta; de 155 a 199, hizo un giro a la izquierda; entre 199 y 289 , se desplazó por la segunda recta; de 289 a 331, giró su cuerpo; de 331 a 386, avanzó por la última recta.

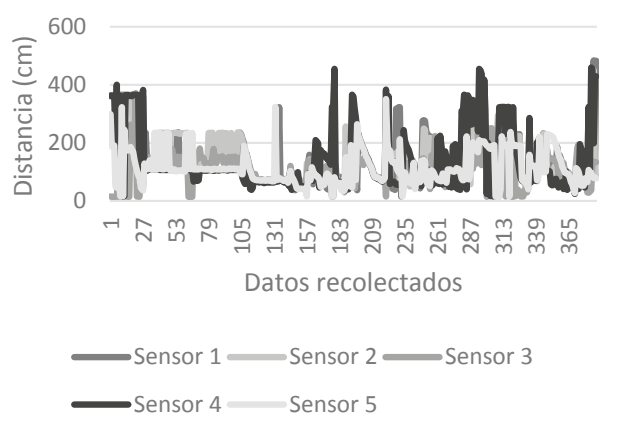

Fig. 9. Datos del participante 4. Fuente: autores.
En la fig. 10, se puede afirmar que el sistema le advirtió al invidente número 5 acerca del primer obstáculo en los datos 1 a 12 . En el rango de 45 a 210 se dirigió por la primera recta; de 210 a 232, hizo un giro a la izquierda; entre 232 y 331 , caminó por la segunda recta; de 331 a 342, giró su cuerpo; de 342 a 386 , se movió por la última recta.

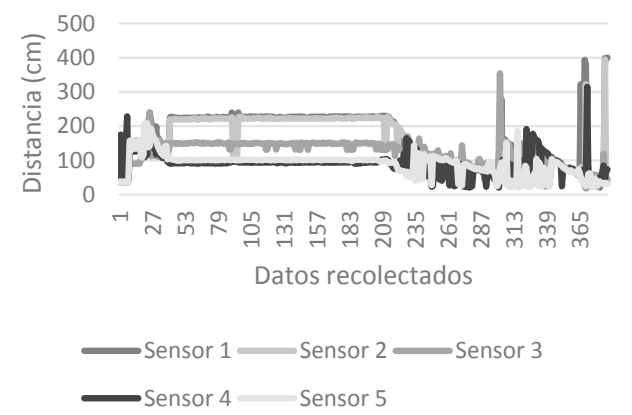

Fig. 10. Datos del participante 5 . Fuente: autores.

En los gráficos anteriores, en las que reflejan la participación de los cinco invidentes, se observa que se acercaron a los diferentes obstáculos teniendo en cuenta la información proporcionada por el sistema. Los rangos cambian de una persona a otra debido a que todos los participantes se desplazaron a diferentes velocidades.

En la fig. 11, se puede observar que el sistema le advirtió al participante número 6 acerca del primer obstáculo en los datos 1 a 23 . En el rango de 23 a 56, avanzó por la primera recta; de 56 a 133, realizó un giro; entre 133 y 221 , se dirigió por la segunda recta; de 221 a 289, giró su cuerpo; de 289 a 386, caminó por la última recta.

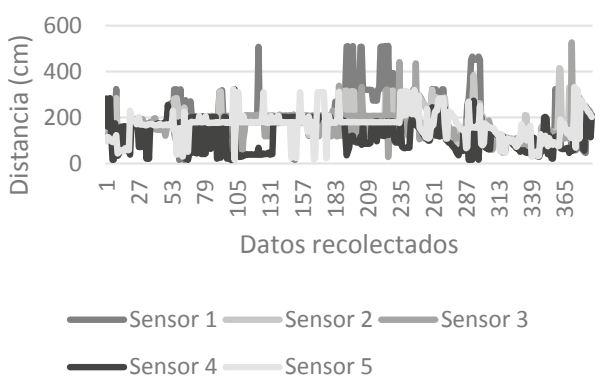

Fig. 11. Datos del participante 6 . Fuente: autores.

En la fig. 12, se puede afirmar que el sistema le advirtió al participante número 7 acerca del primer obstáculo en el dato 9. En el rango de 9 a 97 se movió por la primera recta; de 97 a 113, hizo un giro a la izquierda; entre 121 y 225 , se desplazó por la segunda recta; de 225 a 257 , giró su cuerpo; de 257 a 273 , avanzó por la última recta. 

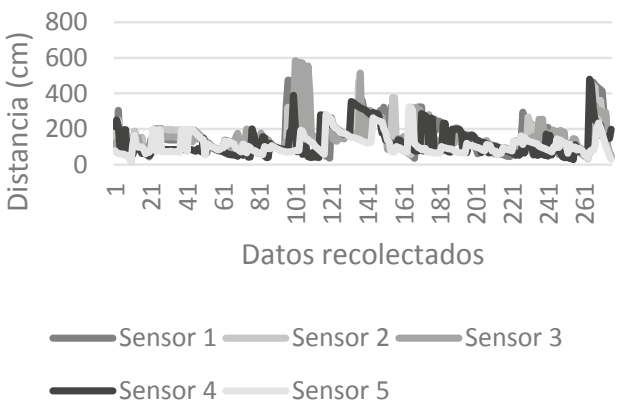

Fig. 12. Datos del participante 7. Fuente: autores.

En la fig. 13, se puede ver que el sistema le advirtió al participante número 8 acerca del primer obstáculo en los datos 1 a 41 . En el rango de 41 a 81 se dirigió por la primera recta; de 81 a 153 hizo un giro a la izquierda; entre 153 y 193, caminó por la segunda recta; de 201 a 241, giró su cuerpo; de 241 a 273 , se movió por la última recta.

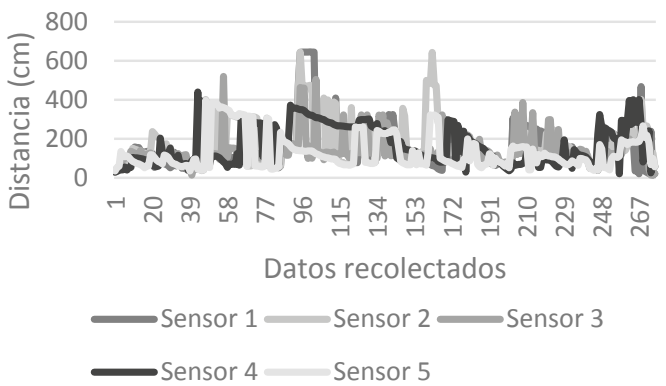

Fig. 13. Datos del participante 8 . Fuente: autores.

En la fig. 14, se puede apreciar que el sistema le advirtió al participante número 9 acerca del primer obstáculo en los datos 1 a 33. En el rango de 33 a 129 se desplazó por la primera recta; de 129 a 177, hizo un giro a la izquierda; entre 185 y 225 , avanzó por la segunda recta; de 225 a 241, giró su cuerpo; de 241 a 381 , se dirigió por la última recta.

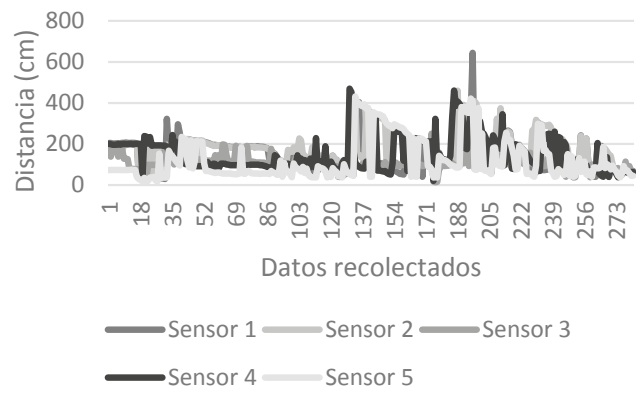

Fig. 14. Datos del participante 9. Fuente: autores.

En la fig. 15, se puede deducir que el sistema le advirtió al participante número 10 acerca del primer obstáculo en los datos 1 a 25 . En el rango de 25 a 41, caminó por la primera recta; de 41 a 65 , hizo un giro a la izquierda; entre 65 y 101, se movió por la segunda recta; de 101 a 105, giró su cuerpo; de 105 a 121, se desplazó por la última recta.
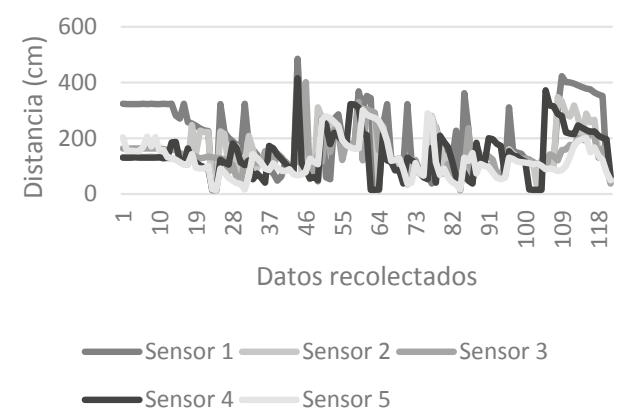

Fig. 15. Datos del participante 10. Fuente: autores.

En las figuras anteriores en las que participaron personas que pueden ver, se observa que se acercaron a los diferentes obstáculos teniendo en cuenta la información proporcionada por el sistema. Los rangos cambian de una persona a otra debido a que todos los participantes se desplazan a diferentes velocidades, además, cabe destacar que algunas de las

Tabla 14. Cuartil de los Resultados de los invidentes.

\begin{tabular}{|c|c|c|c|c|c|}
\hline & Participante 1 & Participante 2 & Participante 3 & Participante 4 & Participante 5 \\
\hline Cuartil 1a & $71,12 \mathrm{~cm}$ & $91,44 \mathrm{~cm}$ & $78,74 \mathrm{~cm}$ & $71,12 \mathrm{~cm}$ & $81,28 \mathrm{~cm}$ \\
\hline Cuartil 2a & $102,87 \mathrm{~cm}$ & $110,49 \mathrm{~cm}$ & $111,76 \mathrm{~cm}$ & $110,49 \mathrm{~cm}$ & $100,33 \mathrm{~cm}$ \\
\hline Cuartil 3a & $156,21 \mathrm{~cm}$ & $201,93 \mathrm{~cm}$ & $191,77 \mathrm{~cm}$ & $154,30 \mathrm{~cm}$ & $148,59 \mathrm{~cm}$ \\
\hline
\end{tabular}

Fuente: autores.

Tabla 15. Cuartil de los Resultados de los Participantes Sin PROBlemas de Visión.

\begin{tabular}{|c|c|c|c|c|c|}
\hline & Participante 6 & Participante 7 & Participante 8 & Participante 9 & Participante 10 \\
\hline Cuartil 1b & $107,95 \mathrm{~cm}$ & $81,28 \mathrm{~cm}$ & $80,01 \mathrm{~cm}$ & $78,74 \mathrm{~cm}$ & $95,25 \mathrm{~cm}$ \\
\hline Cuartil 2b & $175,26 \mathrm{~cm}$ & $115,57 \mathrm{~cm}$ & $123,19 \mathrm{~cm}$ & $109,22 \mathrm{~cm}$ & $130,81 \mathrm{~cm}$ \\
\hline Cuartil 3b & $204,47 \mathrm{~cm}$ & $165,1 \mathrm{~cm}$ & $200,66 \mathrm{~cm}$ & $190,5 \mathrm{~cm}$ & $193,04 \mathrm{~cm}$ \\
\hline
\end{tabular}

Fuente: autores. 
personas que no eran invidentes, al colocarse el antifaz negro que les impedía completamente la visión y al no conocer el recorrido, sintieron inseguridad.

En la tabla 14 y en la tabla 15, se muestran respectivamente los resultados obtenidos por los invidentes y los participantes con el indicador estadístico. Las distancias pueden variar dependiendo del ángulo de detección de los sensores.

A continuación, se muestran las gráficas obtenidas por el indicador estadístico.

En la fig. 16, se puede observar el cuartil 1 equivalente al $25 \%$ de los datos recolectados en el recorrido total. El cuartil 1a corresponde a los invidentes y el cuartil $1 \mathrm{~b}$ corresponde a las personas que ven. En este cuartil, los invidentes se acercan a menor distancia de los obstáculos debido al uso del bastón que se complementa con el sistema anticolisión. Mientras que los participantes que no usan bastón confían en el dispositivo y se observa que los mantiene a una distancia similar a la del bastón.

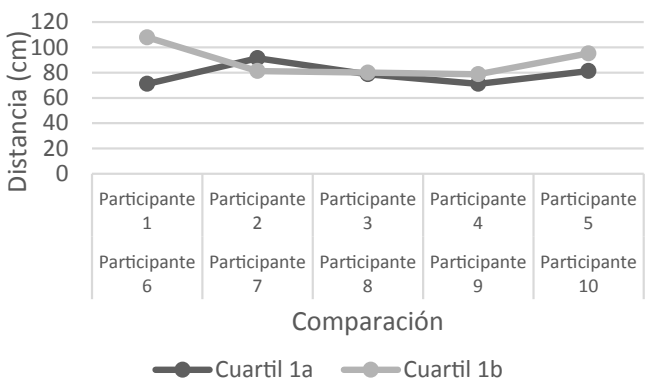

Fig. 16. Cuartil 1.

Fuente: autores.

En la fig. 17, se muestra el cuartil 2, correspondiente al $50 \%$ de los datos recolectados en el recorrido total. El cuartil 2 a corresponde a los invidentes y el cuartil $2 \mathrm{~b}$ corresponde a las personas que ven. Los invidentes, en la mayor parte del recorrido, estuvieron a una distancia de $100 \mathrm{~cm}$ a $120 \mathrm{~cm}$ de los objetos, mientras que los participantes estuvieron a una distancia de $100 \mathrm{~cm}$ a $180 \mathrm{~cm}$ de los objetos, estas distancias dependen del ángulo de posición de los sensores.

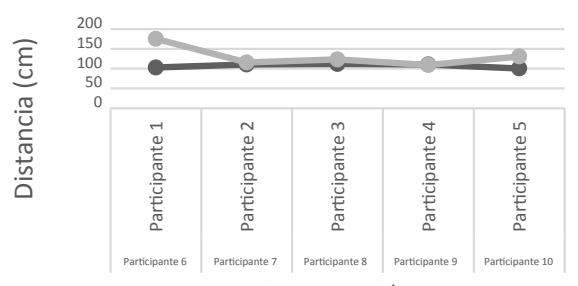

Comparación

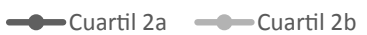

Fig. 17. Cuartil 2.

Fuente: autores.
En la fig. 18, se muestra el cuartil 3, que representa el $75 \%$ de los datos recolectados en el recorrido total. El cuartil 3a corresponde a los invidentes y el cuartil $3 \mathrm{~b}$ corresponden a las personas que ven. En este cuartil se refleja que tanto los invidentes como los participantes se alejaron de los objetos entre $150 \mathrm{~cm}$ a $200 \mathrm{~cm}$, siendo similar al uso del bastón.
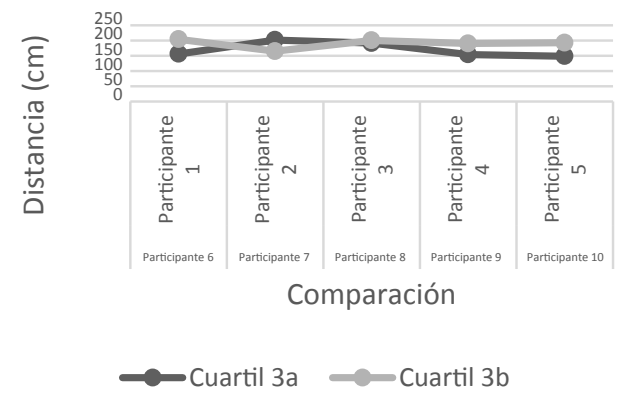

Fig. 18. Cuartil 3.

Fuente: autores.

En la detección de objetos en movimiento se realiza la prueba con un vehículo. En esta prueba se van a tener en cuenta los resultados de los 5 sensores delanteros con RNAE. Para ello, se ubica el vehículo a una distancia de $9 \mathrm{~m}$ del participante y se procederá a acercar el vehículo hacia los participantes, como se puede observar en la fig. 19.

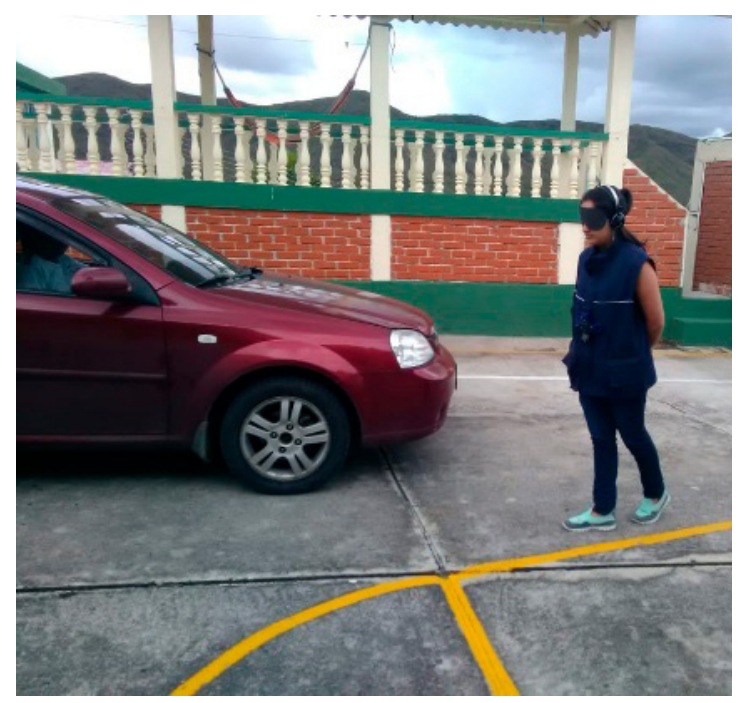

Fig. 19. Detección de vehículo en movimiento con sensores delanteros. Fuente: autores.

$\mathrm{Al}$ realizar la prueba con los 10 participantes, se obtuvieron los siguientes resultados.

En la fig. 20 del participante 1, el vehículo se detecta en el rango de 7 a 19 datos, así, el invidente se aleja del peligro de 19 a 23 . 


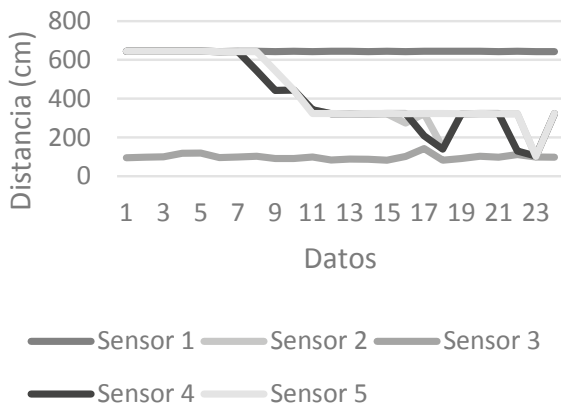

Fig. 20. Datos del participante 1 con sensores frontales. Fuente: autores.

En la fig. 21 del participante 2, el vehículo es detectado en el rango 9 a 13 datos, $y$, en el rango de 12 a 14 , el invidente se aleja del vehículo.

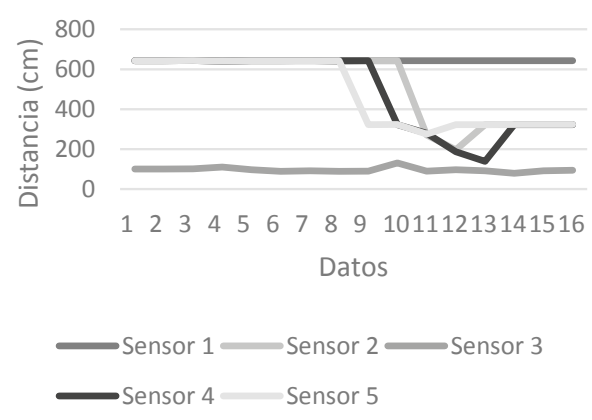

Fig. 21. Datos del participante 2 con sensores frontales. Fuente: autores.

En la fig. 22 del participante 3, el vehículo es detectado en el rango de 6 a 11 datos; en el rango de 10 a 12 , el invidente se aleja del vehículo.
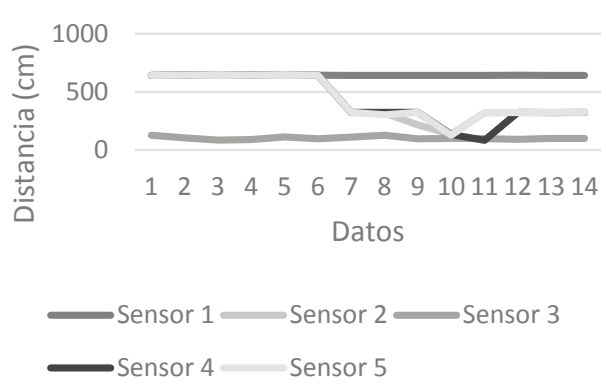

Fig. 22. Datos del participante 3 con sensores frontales. Fuente: autores.

En la fig. 23 del participante 4, el vehículo es detectado en el rango de 6 a 10 datos; en el rango de 9 a 11 , el invidente se aleja del vehículo.

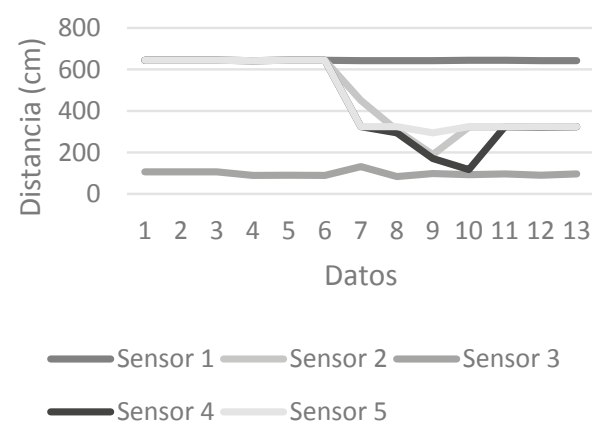

Fig. 23. Datos del participante 4 con sensores frontales. Fuente: autores.

En la fig. 24 del participante 5, el vehículo es detectado en el rango de 12 a 15 datos; el invidente se aleja del peligro en el rango de 14 a 16.

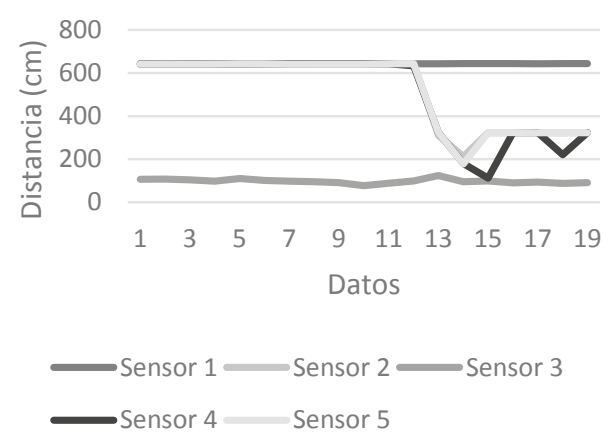

Fig. 24. Datos del participante 5 con sensores frontales, Fuente: autores.

En la fig. 25 del participante 6, el vehículo es detectado en el rango de 13 a 18 datos; el participante se aleja del peligro en el rango de 17 a 19.

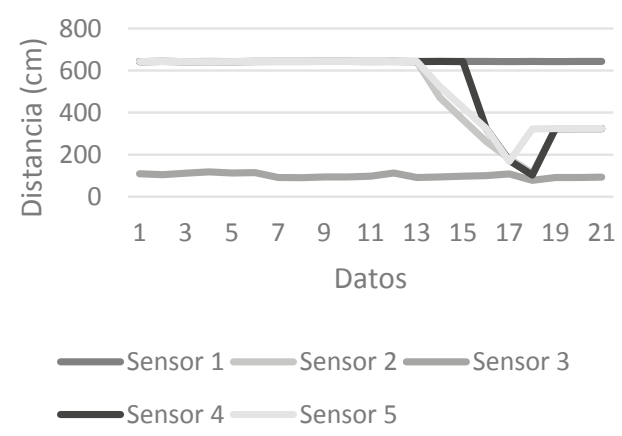

Fig. 25. Datos del participante 6 con sensores frontales. Fuente: autores.

En la fig. 26 del participante 7, el vehículo es detectado en el rango de 11 a 15 datos; el participante se aleja del peligro en el rango de 15 a 16. 


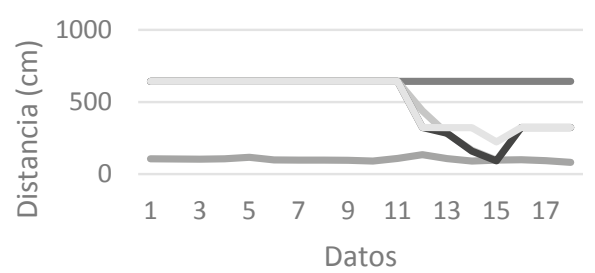

$\longrightarrow$ Sensor $1 \longrightarrow$ Sensor $2 \longrightarrow$ Sensor 3

Sensor $4=$ Sensor 5

Fig. 26. Datos del participante 7 con sensores frontales. Fuente: autores.

En la fig. 27 del participante 8, el vehículo es detectado en el rango de 10 a 14 datos; el participante se aleja del peligro en el rango de 14 a 15 .

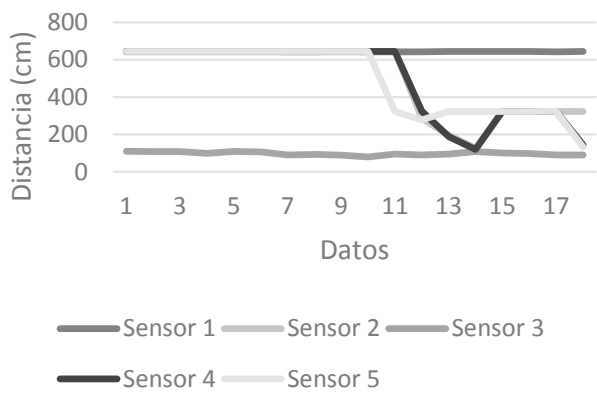

Fig. 27. Datos del participante 8 con sensores frontales. Fuente: autores.

En la fig. 28 del participante 9, el vehículo es detectado en el rango de 15 a 19 datos; el participante se aleja del peligro en el rango de 18 a 20 .

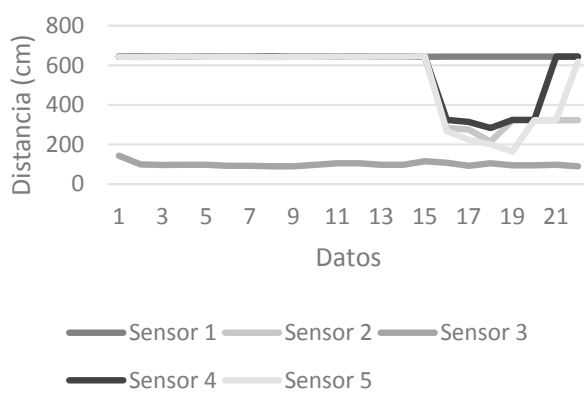

Fig. 28. Datos del participante 9 con sensores frontales. Fuente: autores.

En la fig. 29 del participante 10, el vehículo es detectado en el rango de 6 a 9 datos; el participante se aleja del peligro en el rango de 9 a 13.

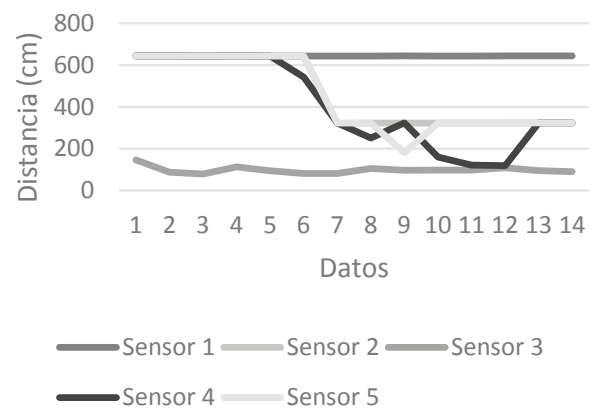

Fig. 29. Datos del participante 10 con sensores frontales. Fuente: autores.

A continuación, en la tabla 16 y en la tabla 17 , se muestran respectivamente los resultados obtenidos por los invidentes y los participantes con el indicador estadístico.

Tabla 16. Cuartil de los Resultados De Los invidentes Con objeto en Movimiento 1.

\begin{tabular}{|l|c|c|c|c|c|}
\hline & $\begin{array}{c}\text { Participante } \\
1\end{array}$ & $\begin{array}{c}\text { Participante } \\
2\end{array}$ & $\begin{array}{c}\text { Participante } \\
3\end{array}$ & $\begin{array}{c}\text { Participante } \\
4\end{array}$ & $\begin{array}{c}\text { Participante } \\
5\end{array}$ \\
\hline Cuartil 1a & $193,36 \mathrm{~cm}$ & $274,32 \mathrm{~cm}$ & $156,21 \mathrm{~cm}$ & $294,64 \mathrm{~cm}$ & $266,03 \mathrm{~cm}$ \\
\hline Cuartil 2a & $323,85 \mathrm{~cm}$ & $641,35 \mathrm{~cm}$ & $323,85 \mathrm{~cm}$ & $323,85 \mathrm{~cm}$ & $641,35 \mathrm{~cm}$ \\
\hline Cuartil 3a & $643,38 \mathrm{~cm}$ & $642,62 \mathrm{~cm}$ & $642,62 \mathrm{~cm}$ & $643,89 \mathrm{~cm}$ & $642,62 \mathrm{~cm}$ \\
\hline
\end{tabular}

Fuente: autores.

Tabla 17. Cuartil de los Resultados de los participantes Con objeto en movimiento 1.

\begin{tabular}{|l|c|c|c|c|c|}
\hline & $\begin{array}{c}\text { Participante } \\
6\end{array}$ & $\begin{array}{c}\text { Participante } \\
7\end{array}$ & $\begin{array}{c}\text { Participante } \\
8\end{array}$ & $\begin{array}{c}\text { Participante } \\
9\end{array}$ & $\begin{array}{c}\text { Participante } \\
10\end{array}$ \\
\hline Cuartil 1b & $262,89 \mathrm{~cm}$ & $238,06 \mathrm{~cm}$ & $190,18 \mathrm{~cm}$ & $277,50 \mathrm{~cm}$ & $198,12 \mathrm{~cm}$ \\
\hline Cuartil $2 \mathrm{~b}$ & $642,62 \mathrm{~cm}$ & $642,62 \mathrm{~cm}$ & $642,62 \mathrm{~cm}$ & $642,62 \mathrm{~cm}$ & $323,85 \mathrm{~cm}$ \\
\hline Cuartil $3 \mathrm{~b}$ & $643,89 \mathrm{~cm}$ & $643,57 \mathrm{~cm}$ & $643,89 \mathrm{~cm}$ & $643,89 \mathrm{~cm}$ & $642,62 \mathrm{~cm}$ \\
\hline
\end{tabular}

Fuente: autores. 
A continuación, se muestran las gráficas obtenidas por el indicador estadístico.

En la fig. 30 se aprecia que los invidentes estuvieron más cerca del vehículo con respecto a los otros participantes. Es decir, que lo más cercano que estuvieron al vehículo fueron $160 \mathrm{~cm}$, mientras que los otros participantes se mantuvieron a $190 \mathrm{~cm} . \mathrm{El}$ cuartil 1a corresponde a los invidentes y el cuartil $1 \mathrm{~b}$ corresponde a las personas que ven; en todos los casos se mantuvieron las personas a salvo a una distancia considerable.

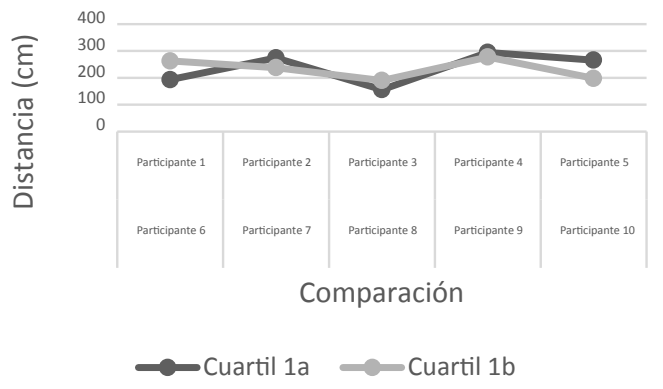

Fig. 30. Cuartil 1 sensores frontales. Fuente: autores.

En la fig. 31, los invidentes estuvieron mayor tiempo cerca del vehículo sin alejarse, con una distancia de $310 \mathrm{~cm}$, mientras que los otros participantes a 645 $\mathrm{cm}$ se distanciaron; esto se debe a que los invidentes se alejaron del peligro un poco más lento que los demás participantes. El cuartil 2a corresponde a los invidentes y el cuartil $2 \mathrm{~b}$ corresponde a las personas que ven.

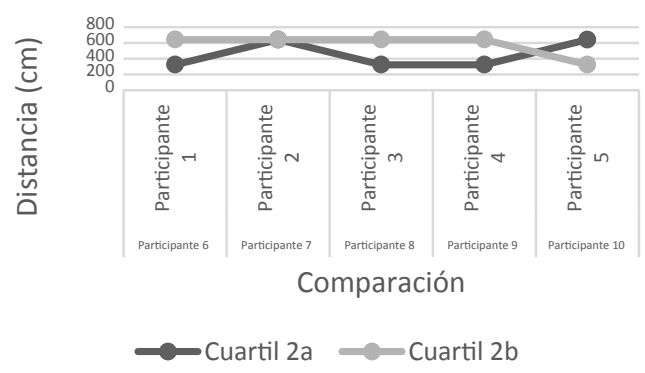

Fig. 31. Cuartil 2 sensores frontales.

Fuente: autores.

En la fig. 32 se observa que en el $75 \%$, que le corresponde al cuartil 3, la mayor parte del escenario no hubo peligro para los participantes debido a que se alejaron a una distancia grande del vehículo.

El cuartil 3a corresponde a los invidentes y el cuartil $3 \mathrm{~b}$ corresponde a las personas que ven.

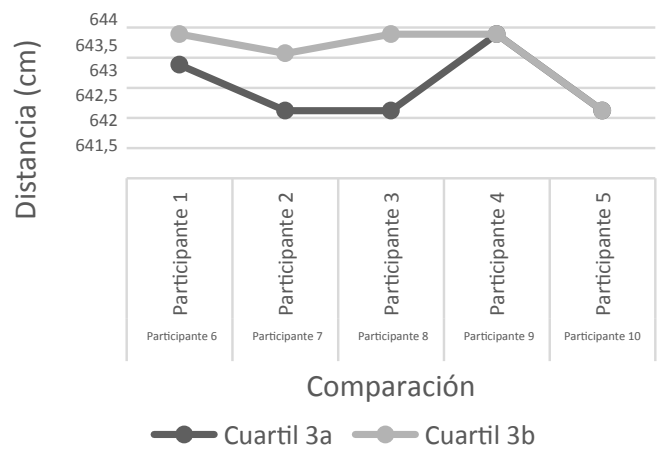

Fig. 32. Cuartil 3 sensores frontales. Fuente: autores.

En este escenario se van a tener en cuenta los resultados de los 5 sensores posteriores con RNAE. Para ello se ubica al vehículo a una distancia de $7 \mathrm{~m}$ del participante y se procederá a acercar el vehículo a los participantes como se puede observar en la fig. 33 .

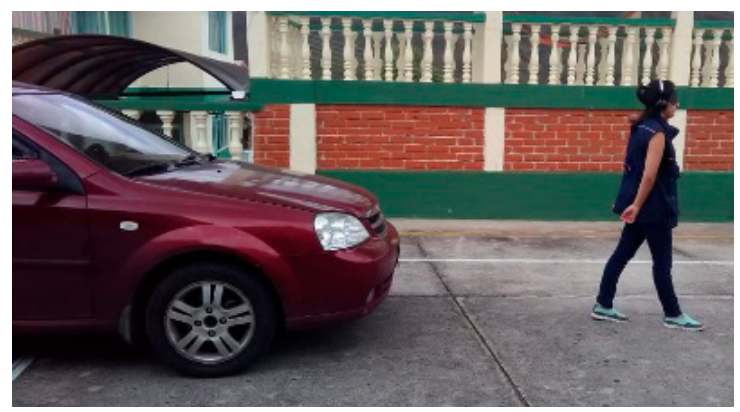

Fig. 33. Detección de vehículo en movimiento con sensores posteriores.

Fuente: autores.

$\mathrm{Al}$ realizar la prueba con los 10 participantes, se obtuvieron los siguientes resultados.

En la fig. 34 del participante 1, se puede observar que se detecta movimiento desde el frente, desde el rango 7 a 19 datos, y el invidente se aleja del peligro de 11 a 17 .

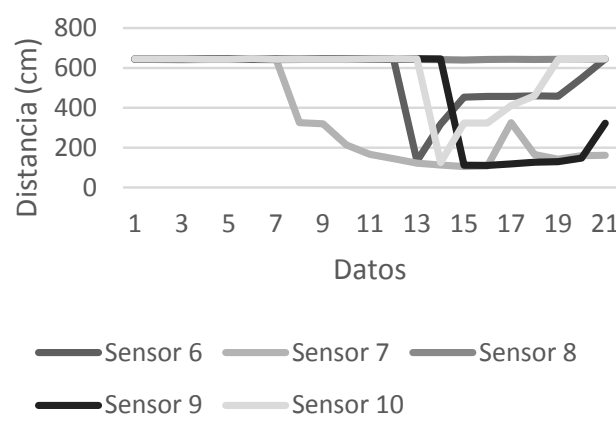

Fig. 34. Datos del participante 1 con sensores posteriores. Fuente: autores. 
En la fig. 35 del participante 2, el vehículo es detectado en el rango de 9 a 13 datos, y en el rango de 12 a 16 , el invidente se aleja del vehículo.

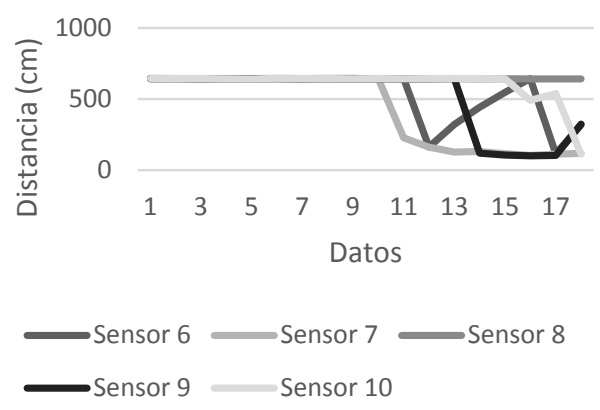

Fig. 35. Datos del participante 2 con sensores posteriores. Fuente: autores.

En la fig. 36 del participante 3, el vehículo es detectado en el rango de 9 a 11 datos; en el rango de 10 a 17, el invidente se aleja del vehículo.

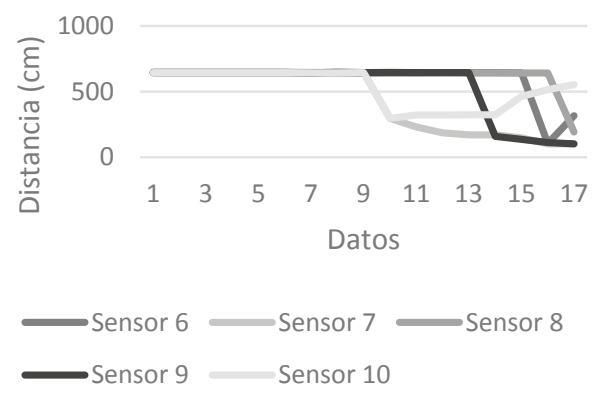

Fig. 36. Datos del participante 3 con sensores posteriores. Fuente: autores.

En la fig. 37 del participante 4, el vehículo es detectado en el rango de 7 a 9 datos; en el rango de 9 a 15, el invidente se aleja del vehículo.
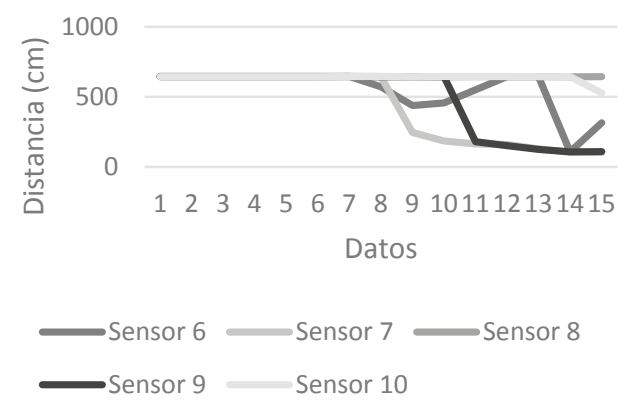

Fig. 37. Datos del participante 4 con sensores posteriores.

$$
\text { Fuente: autores. }
$$

En la fig. 38 del participante 5 , el vehículo es detectado en el rango de 6 a 9 datos; el invidente se aleja del peligro en el rango de 9 a 16.

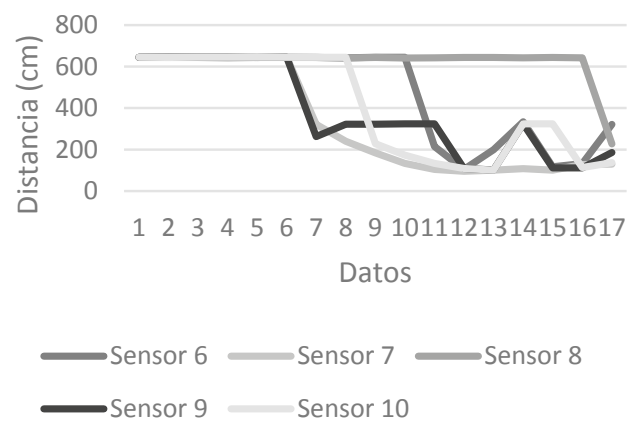

Fig. 38. Datos del participante 5 con sensores posteriores. Fuente: autores.

En la fig. 39 del participante 6, el vehículo es detectado en el rango de 7 a 11 datos; el participante se aleja del peligro en el rango de 11 a 17 .

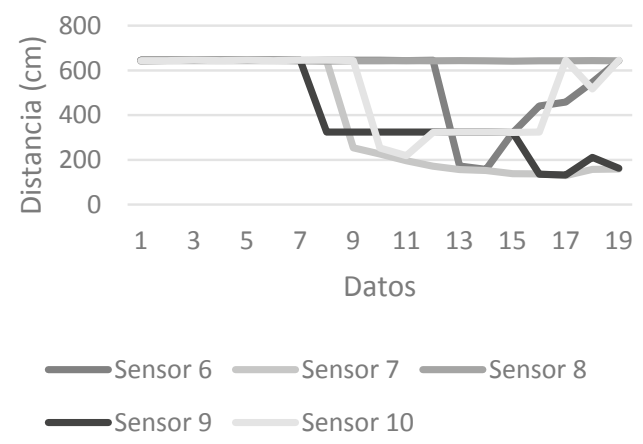

Fig. 39. Datos del participante 6 con sensores posteriores. Fuente: autores.

En la fig. 40 del participante 7, el vehículo es detectado en el rango de 5 a 8 datos; el participante se aleja del peligro en el rango de 8 a 14 .
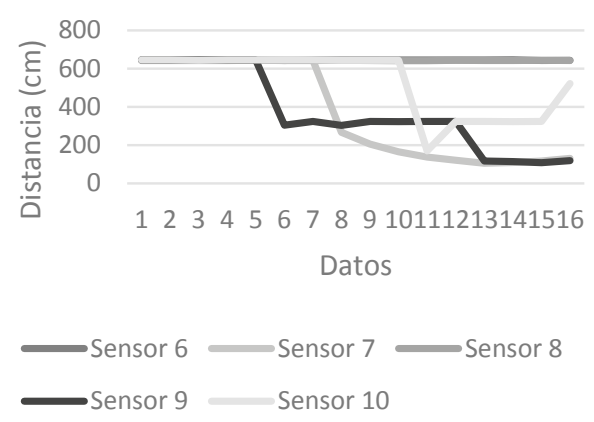

Fig. 40. Datos del participante 7 con sensores posteriores. Fuente: autores.

En la fig. 41 del participante 8, el vehículo es detectado en el rango de 6 a 11 datos; el participante se aleja del peligro en el rango de 11 a 16 . 


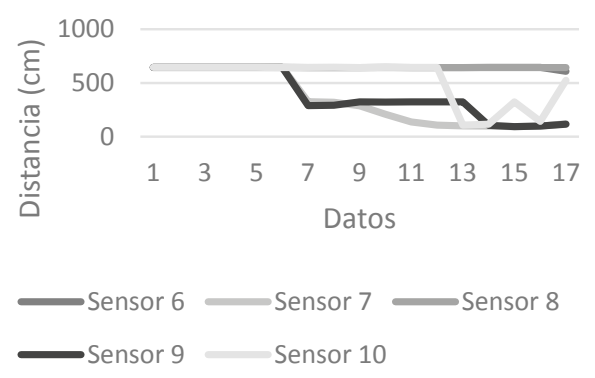

Fig. 41. Datos del participante 8 con sensores posteriores. Fuente: autores

En la fig. 42 del participante 9, el vehículo es detectado en el rango de 7 a 12 datos; el participante se aleja del peligro en el rango de 12 a 17.

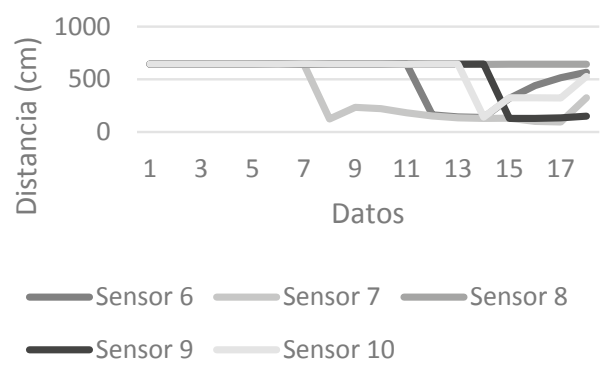

Fig. 42. Datos del participante 9 con sensores posteriores. Fuente: autores.
En la fig. 43 del participante 10, el vehículo es detectado en el rango de 7 a 11 datos; el participante se aleja del peligro en el rango de 11 a 16.
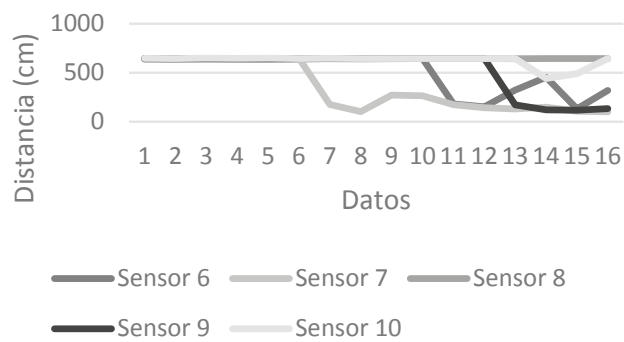

Fig. 43. Datos del participante 10 con sensores posteriores. Fuente: autores.

En la tabla 18 y en la tabla 19 , se muestran respectivamente los resultados obtenidos por los invidentes y los participantes con el indicador estadístico.

A continuación, se muestran las gráficas obtenidas por el indicador estadístico.

En la fig. 44 se muestra el cuartil 1, que representa el $25 \%$ de los datos recolectados. Los invidentes estuvieron más alejados del vehículo de $400 \mathrm{~cm}$ a $645 \mathrm{~cm}$, a excepción del invidente 5 . Lo más cercano que estuvo al vehículo fue de $190 \mathrm{~cm}$, mientras que los otros participantes se mantuvieron a $310 \mathrm{~cm} \mathrm{y}$ máximo $450 \mathrm{~cm}$ antes de alejarse del vehículo. El cuartil 1a corresponde a los invidentes y el cuartil $1 \mathrm{~b}$ corresponde a las personas que ven.

Tabla 18. Cuartil de los Resultados de los invidentes con objeto en movimiento 2.

\begin{tabular}{|c|c|c|c|c|c|}
\hline & $\begin{array}{c}\text { Participante } \\
1\end{array}$ & $\begin{array}{c}\text { Participante } \\
2\end{array}$ & $\begin{array}{c}\text { Participante } \\
3\end{array}$ & $\begin{array}{c}\text { Participante } \\
4\end{array}$ & $\begin{array}{c}\text { Participante } \\
5\end{array}$ \\
\hline $\begin{array}{c}\text { Cuartil } \\
1 \mathrm{a}\end{array}$ & $411,48 \mathrm{~cm}$ & $641,35 \mathrm{~cm}$ & $515,62 \mathrm{~cm}$ & $607,06 \mathrm{~cm}$ & $184,15 \mathrm{~cm}$ \\
\hline $\begin{array}{c}\text { Cuartil } \\
2 \mathrm{a}\end{array}$ & $643,89 \mathrm{~cm}$ & $643,89 \mathrm{~cm}$ & $643,89 \mathrm{~cm}$ & $643,89 \mathrm{~cm}$ & $642,62 \mathrm{~cm}$ \\
\hline $\begin{array}{c}\text { Cuartil } \\
3 \mathrm{a}\end{array}$ & $645,16 \mathrm{~cm}$ & $645,16 \mathrm{~cm}$ & $645,16 \mathrm{~cm}$ & $645,16 \mathrm{~cm}$ & $645,16 \mathrm{~cm}$ \\
\hline
\end{tabular}

Fuente: autores.

Tabla 19. Cuartil de los Resultados de los participantes con objeto en movimiento 2.

\begin{tabular}{|c|c|c|c|c|c|}
\hline & $\begin{array}{c}\text { Participante } \\
6\end{array}$ & $\begin{array}{c}\text { Participante } \\
7\end{array}$ & $\begin{array}{c}\text { Participante } \\
8\end{array}$ & $\begin{array}{c}\text { Participante } \\
9\end{array}$ & $\begin{array}{c}\text { Participante } \\
10\end{array}$ \\
\hline $\begin{array}{c}\text { Cuartil } \\
1 \mathrm{~b}\end{array}$ & $323,85 \mathrm{~cm}$ & $323,85 \mathrm{~cm}$ & $323,85 \mathrm{~cm}$ & $354,01 \mathrm{~cm}$ & $451,17 \mathrm{~cm}$ \\
\hline $\begin{array}{c}\text { Cuartil } \\
2 \mathrm{~b}\end{array}$ & $642,62 \mathrm{~cm}$ & $643,26 \mathrm{~cm}$ & $643,89 \mathrm{~cm}$ & $643,89 \mathrm{~cm}$ & $643,89 \mathrm{~cm}$ \\
\hline $\begin{array}{c}\text { Cuartil } \\
3 \mathrm{~b}\end{array}$ & $645,16 \mathrm{~cm}$ & $645,16 \mathrm{~cm}$ & $645,16 \mathrm{~cm}$ & $645,16 \mathrm{~cm}$ & $645,16 \mathrm{~cm}$ \\
\hline
\end{tabular}

Fuente: autores. 


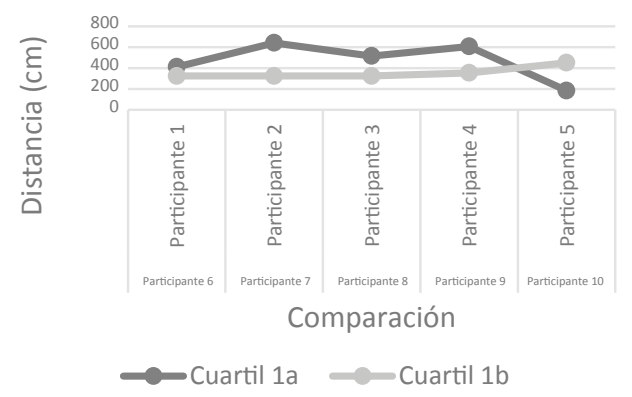

Fig. 44. Cuartil 1 sensores posteriores. Fuente: autores.

En la fig. 45 se observa el cuartil 2, que representa el $50 \%$ de los datos recolectados. Los participantes se mantuvieron fuera de peligro. El cuartil 2 a corresponde a los invidentes y el cuartil 2 b corresponde a las personas que ven.

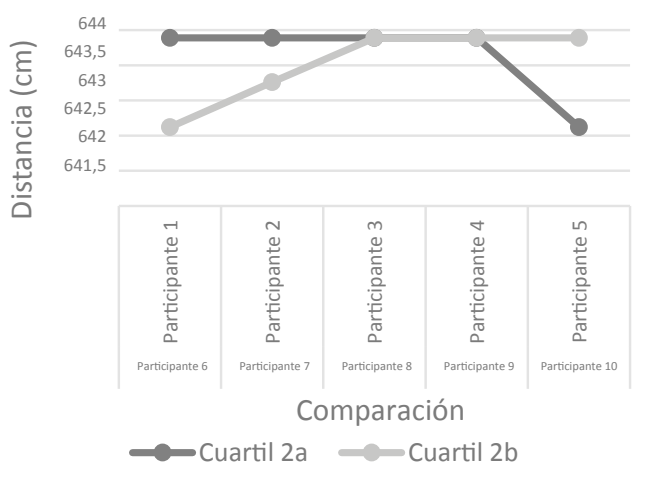

Fig. 45. Cuartil 2 sensores posteriores. Fuente: autores.

En la fig. 46 se observa que en el $75 \%$, que le corresponde al cuartil 3, la mayor parte del escenario no hubo peligro para los participantes. El cuartil 3a corresponde a los invidentes y el cuartil 3b corresponde a las personas que ven.

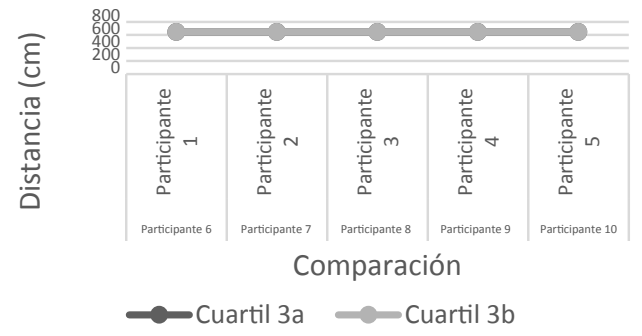

Fig. 46. Cuartil 3 sensores posteriores. Fuente: autores.

Después de verificar el funcionamiento del sistema anticolisión detectando objetos en movimiento, se llegó a las siguientes conclusiones:

- El sistema anticolisión funciona detectando la presencia de objetos en movimiento.
- Teniendo en cuenta las tablas y las gráficas, se observa que los rangos de distancia de detección de los diferentes objetos con la red neuronal evolutiva son efectivos, presentando mayor seguridad para el invidente.

- Las alertas de la presencia de objetos dadas por medio del módulo de sonido fueron efectivas en el tiempo en que la red neuronal evolutiva detectó el objeto.

\section{Conclusiones y trabajo Futuro}

Se crearon redes neuronales artificiales a partir del algoritmo genético cooperativo coevolutivo (AGCC), con el cual se realizó la estructura, modificación y entrenamiento de las redes neuronales, pasando por operadores de selección, cruce y mutación. El sistema utilizó redes neuronales recurrentes cubriendo el rango requerido.

Se probó la funcionalidad de la matriz de definición de red (MDR) para elaborar redes neuronales evolutivas. Una vez realizada la MDR, se creó una red neuronal artificial para luego ser entrenada y proporcionar la respuesta.

Se aplicó la cooperatividad, donde el individuo que obtuviera mejores resultados ayudaría al que estuviera con bajo valor de aptitud. Si no se encontraba la respuesta pasaban de nuevo los mejores individuos a ser seleccionados en una nueva generación, es decir, si la respuesta no era la deseada, volverían a la parte de selección, hasta obtenerse la respuesta deseada.

El hardware se implementó con 10 sensores ubicados para detectar objetos provenientes desde la parte superior, frontal, inferior, derecha e izquierda; estos se conectaron al módulo Arduino, que procesa y filtra la información proporcionada por los sensores. Luego, la red neuronal evolutiva es ejecutada con los datos de los sensores. La respuesta de la red neuronal es binaria para cada sensor advirtiendo si existe o no peligro. En el caso de que detecte un objeto en movimiento o estático alertará al invidente a través del módulo de sonido que contiene los archivos de audio en mp3. El dispositivo se alimentó con batería recargable.

El programa realizó varias redes neuronales, generando en cada ejecución 10 cromosomas con los que, al ser entrenados con el AGCC y tras aplicar la cooperatividad, se obtuvieron las mejores redes neuronales anticolisión, teniendo en cuenta un tiempo definido. De esta forma, funcionó efectivamente para la detección de obstáculos estáticos y con movimiento.

En el sistema anticolisión para invidentes se observóla eficacia de las redes neuronales entrenadas con el algoritmo genético cooperativo coevolutivo. Se obtuvieron resultados aproximados al vector objetivo, detectando objetos tanto estáticos como en movimiento y, por ende, proporcionando seguridad al invidente pues le evitó colisiones con estos. 
El dispositivo resulta más familiar para las personas invidentes, quienes normalmente hacen uso de la audición para poder guiarse, por este motivo se adaptaron más fácilmente al dispositivo a pesar de no conocer el escenario.

Las personas que están acostumbradas a guiarse por el sentido de la vista, al sentirse privadas de la visión con el uso del antifaz de color negro, de un momento a otro, sintieron temor y, al estar en un lugar desconocido, algunos de ellos no lograron concentrarse en las señales de prevención que les enviaba el dispositivo.

Se recomienda para trabajos futuros buscar mejores sensores que operen a una mayor velocidad de adquisición de datos, como los sensores de efecto Doppler y añadirle módulos de posicionamiento.

\section{FinANCIAMIENTO}

Artículo de investigación científica derivado del proyecto de investigación "Sistema de reconocimiento de obstáculos". Proyecto financiado por la Universidad del Cauca (Popayán, Colombia) 2017. Fecha de inicio: junio de 2015. Fecha de finalización: diciembre de 2017.

\section{REFERENCIAS}

[1] J. Mosquera and D. Rodríguez, "Sistema de reconocimiento de obstáculos para movilidad de Invidentes," tesis de pregrado, Universidad del Cauca, 2014.

[2] T. Praczyk, "Neural anti-collision system for autonomous surface vehicle," Neurocomputing, vol. 149, pp. 559-572, 2015. https://doi.org/10.1016/j.neucom.2014.08.018

[3] D. Curran and C. O'Riordan, "Increasing population diversity through cultural learning," Adaptive Behavior, vol. 14, no. 4, pp. 315-338, 2006. https://doi. org/10.1177/1059712306072335

[4] G. Miller, P. Todd, and S. Hegde, "Designing neural networks using genetic algorithms," Proceedings of the 3rd International Conference on Genetic Algorithms, pp. 379-384, 1989.

[5] X. Yao and Y. Liu, "A new evolutionary system for evolving artificial neural networks," IEEE transactions on neural networks, vol. 8, no. 3, pp. 694-713, 1997. https:// doi.org/10.1109/72.572107

[6] N. García, C. Hervás, and J. Mu-oz, "Multi-objective cooperative coevolution of artificial neural networks," Neural Networks, vol. 15, no. 10, pp. 1259-1278, 2002. https://doi.org/10.1016/S0893-6080(02)00095-3

[7] K. Ohkura, T. Yasuda, Y. Kawamatsu, Y. Matsumura, and K. Ueda, "MBEANN: Mutation-based evolving artificial neural networks," Neural Networks, pp. 936-945, 2007. https://doi.org/10.1007/978-3-540-74913-4_94

[8] A. Azzini and A. Tettamanzi, "A new genetic approach for neural network design and optimization," tesis doctoral, Universidad de Milán, 2008.

[9] A. Tallón, "Nuevos modelos de redes neuronales evolutivas para clasificación: aplicación a unidades producto y unidades sigmoide," tesis doctoral, Universidad de Sevilla, 2013.

[10] A. Carvalho, "A cooperative coevolutionary genetic algorithm for learning bayesian network structures," Proceedings of the 13th Annual Genetic and Evolutionary Computation Conference, no. 1, pp. 1131-1138, 2011. https://doi.org/10.1145/2001576.2001729
Juan David Alvarado Coral recibió el título de ingeniero electrónico en el año 2013 de la Corporación Universitaria Autónoma de Nariño, Pasto, Colombia. Magíster en Automática de la Universidad del Cauca en el 2018, Popayán, Colombia. En sus intereses se incluyen la inteligencia artificial, CAD, CAM y la robótica. https://orcid.org/0000-0003-0122-3284

Elena Muñoz España recibió el título de magíster en Electrónica y Telecomunicaciones en el 2009 de la Universidad del Cauca, Popayán, Colombia. Sus áreas de interés son la visión artificial y los sistemas inteligentes. Actualmente es profesora titular del Departamento de Electrónica, Instrumentación y Control de la Universidad del Cauca. https://orcid. org/0000-0002-3919-563X 